\title{
CÓDIGOS UNIPOLARES PARA APLICAÇÕES EM CDMA ÓPTICO
}

\author{
José Santo Guiscafré Panaro \\ INATEL \\ Caixa Postal 5, 37540-000, Sta. Rita do Sapucaí, M.G. \\ panaro@inatel.br \\ Celso de Almeida * \\ DECOM - FEEC - UNICAMP \\ Caixa Postal 6.101, 13.081-970, Campinas, S.P. \\ celso@decom.fee.unicamp.br
}

\begin{abstract}
Resumo - Diversos esquemas de múltiplo acesso através de divisão por código têm sido propostos para sistemas fotônicos. Em particular, para as aplicações que utilizam o princípio da superposição não-coerente dos campos ópticos, os trabalhos concentram-se na construção de códigos específicos e na obtenção da probabilidade de erro resultante da ação do ruído e/ou interferência presentes no canal. De modo distinto. neste artigo desenvolve-se, inicialmente, uma base teórica para a análise de desempenho que contempla a detecção de sinais unipolares, submetidos a condições de interferência aditiva e estritamente positiva, admitindo o uso tanto de sinalização podal quanto ortogonal. Além disso, analisa-se o desempenho de sistemas CDMA unipolares sob a perspectiva de detecção convencional e, também, para receptores que utilizem a técnica de limitação abrupta. Finalmente, propõe-se uma nova classe de códigos de espalhamento temporal que além de possibilitar uma grande diversidade de seqüências, têm o potencial de fornecer um desempenho superior, em termos de taxa de erro, quando comparados a outros códigos propostos anteriormente.
\end{abstract}

Abstract - Several code-division multiple access schemes have been proposed for photonic systems. Specifically, for such applications using the non-coherent optical fields superposition principle, most works are focused on the construction of specific codes and its error performance analysis, due the action of the channel noise and/or interference. In opposition, this paper establishes first a theoretical basis on the performance analysis of the unipolar signal detection under additive and strictly positive interference, taking in account either podal or orthogonal signaling. Furthermore, the performance of unipolar CDMA systems is investigated under the perspective of standard detection, or hard limiting techniques. Finally. a new class of time-hopping codes is proposed, which allows large sequence diversity. It has potential to achieve better error performance, when compared to the codes investigated earlier.

Palavras-chave: Spread-spectrum, CDMA óptico, sinalização unipolar podal, sinalização unipolar ortogonal, detecção de sinais unipolares, códigos OOC, códigos OTH.

\footnotetext{
${ }^{*}$ Este trabalho foi financiado parcialmente pelo Conselho Nacional de Desenvolvimento Científico e Tecnológico - CNPq
}

\section{INTRODUÇÃO}

Diversas técnicas de CDMA para comunicações ópticas foram propostas nas últimas duas décadas. Durante esse período vários enfoques foram abordados, diversas análises de desempenho foram desenvolvidas e, também. uma série de experimentos para a comprovação dos conceitos foram realizados. No entanto, apesar do grande sucesso do CDMA como uma ferramenta de comunicação em aplicações via rádio, existem, ainda, poucas aplicações comerciais dessa técnica em sistemas fotônicos.

O CDMA é uma técnica que oferece a possibilidade de múltiplo acesso através da utilização de seqüências de espalhamento distintas para cada usuário. A codificação permite que os usuários compartilhem a mesma banda de freqüências e que os mesmos operem assincronamente. A combinação dessas duas características atrativas distinguem o CDMA em relação ao TDMA e ao FDMA. Além disso, outras vantagens aparentes do CDMA nas comunicações ópticas são o atraso de acesso relativamente pequeno (característica essencial em redes locais de comunicação de dados). eficiência de largura de faixa, degradação suave com o aumento de tráfego, e segurança. Outra característica relevante dos sistemas CDMA fotônicos é a possibilidade de se efetuar os processos de codificação e decodificação inteiramente no domínio óptico.

$\mathrm{Na}$ seção 2. faz-se uma revisão de alguns aspectos do CDMA óptico, com ênfase nos seus princípios fundamentais. Na seção 3. uma base teórica para a análise de desempenho dos sistemas CDMA em canais unipolares é desenvolvida. Finalmente, na seção 4. uma classe de códigos com saltos temporais é proposta e analisada.

\section{FUNDAMENTOS}

Esta seção apresenta uma revisão dos princípios de operação fundamentais utilizados nos esquemas de CDMA fotônicos. Para esse propósito, considera-se a existência de uma rede óptica de faixa larga, mostrada esquematicamente na Fig. 1. Os sinais de todos os transmissores são distribuídos entre todos os receptores através de um acoplador óptico em estrela. Cada usuário recebe a adição de todos sinais transmitidos, porém, cada um é capaz de distinguir um determinado 


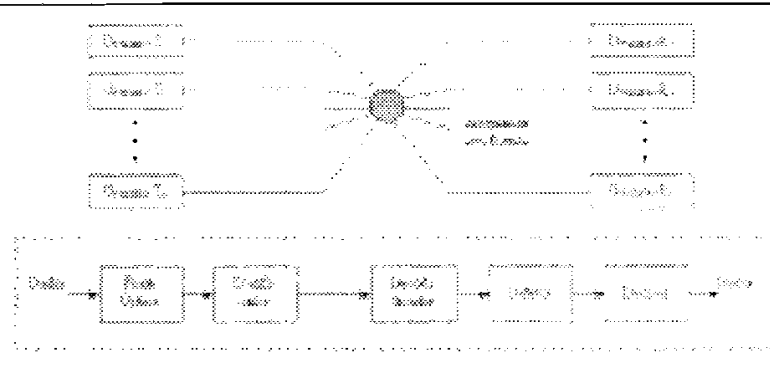

Figura 1. Rede óptica CDMA com acoplador em estrela. Detalhe: processo de transmissão de dados com codificação e decodificação puramente fotônicas.

sinal, dentre os demais sinais interferentes. por intermédio do conhecimento prévio da seqüência de espalhamento empregada no transmissor. A porção inferior da Fig. 1 ilustra um esquema de transmissão e recepção puramente fotônico. Nesse caso, os processos de codificação e decodificação são realizados opticamente, podendo resultar em capacidades de transmissão potencialmente superiores em relação aos esquemas de codificação eletrônicos [1].

A razão entre as relações sinal-interferência na saída e na entrada do decodificador é dada pelo ganho de processamento do sistema, isto é,

$$
(S / J)_{s}=G_{P}(S / J)_{e}
$$

Portanto, o ganho de processamento pode ser interpretado como uma medida da capacidade do sistema para suportar a interferência causada por múltiplos usuários concorrentes. No entanto, ao contrário dos sistemas convencionais de RF, o ganho de processamento dos sistemas CDMA ópticos pode não apresentar uma relação simples com a largura de faixa ocupada pelo sinal.

Em princípio, qualquer combinação de espathamento espacial, temporal e em frequiência pode ser usada na codificação dos dados em um esquema de CDMA óptico. Em conseqüência, existem diferentes enfoques possíveis para a construção de decodificadores fotônicos. Pode-se fazer a distinção entre as técnicas não-coerentes, em que assume-se a adição linear das intensidades luminosas de cada usuário, e as técnicas coerentes, que utilizam o princípio da superposição coerente da luz. As técnicas coerentes requerem o ajuste e controle dos atrasos ópticos da ordem do comprimento de onda empregado, de modo a se obter as fases corretas para a superposição coerente dos campos eletromagnéticos. As dificuldades inerentes a esse último enfoque conduziram a uma ênfase nas técnicas não-coerentes. Todavia, trabalhos recentes têm mostrado que as técnicas coerentes apresentam vantagens distintas e têm potencial para aplicações práticas [1]. No entanto, o presente trabalho é baseado nas técnicas não-coerentes, e por essa razão a outra vertente não será abordada com profundidade.

\subsection{FILTROS CASADOS}

Um receptor de um sistema CDMA deve recuperar o sinal desejado a partir de uma interferência de fundo causada pelos demais usuários, comportando-se como um ruído aditivo. A maneira mais efetiva de alcançar esse objetivo é conseguida por intermédio de um decodificador que maximiza a relação sinal-ruído (SNR). Se o ruído de fundo é branco, tem-se o resultado bem conhecido que a SNR é maximizada através de um filtro casado com o sinal de entrada, cuja resposta ao impulso é igual ao complexo conjugado do sinal desejado $f(t)$, invertido no tempo e atrasado de um intervalo $\tau_{m}$ arbitrário [2], isto é,

$$
h(t)=f^{*}\left(\tau_{m}-t\right)
$$

Para se projetar um filtro de acordo com (2), deve-se conhecer completamente as características do sinal a ser detectado. No entanto, geralmente. essa informação não é conhecida para os sinais usados em CDMA óptico. Por exemplo, o campo fotônico de um diodo emissor de luz é estocástico e, apenas, as suas estatísticas encontram-se disponiveis. Nesse caso, o melhor filtro é aquele que minimiza o erro quadrático médio da estimativa do sinal transmitido [3]. Caso a resposta do codificador seja conhecida completamente e o ruído aditivo seja branco, com uma densidade espectral de potência muito maior que o sinal a ser observado (condição que se aproxima do ambiente CDMA típico), então, pode-se mostrar que o melhor filtro é aquele casado com o codificador [3]. Portanto, sob essas condições, a resposta ao impulso do decodificador deve ser igual ao complexo conjugado da resposta do codificador invertida no tempo, ou seja,

$$
h_{\text {dec }}(t)=h_{\text {cod }}^{*}\left(\tau_{m}-t\right)
$$

Os esquemas baseados em (3), que empregam interferômetros Mach-Zehnder não balanceados e fontes de onda contínua $(\mathrm{CW})$, foram denominados de multiplexagem coerente [4].

A maioria dos esquemas CDMA fotônicos, porém, são não-coerentes, onde a filtragem é realizada baseada na potência do sinal resultante da média temporal das fases ópticas. Assumindo-se que todos os sinais na saída do decodificador não mantêm coerência, o sinal total é produzido pela soma das intensidades individuais das componentes. Neste caso, a resposta ao impulso do decodificador pode ser especificada como a seguir

$$
\left|h_{\text {dec }}(t)\right|^{2} \simeq\left|h_{\text {cod }}\left(\tau_{m}-t\right)\right|^{2}
$$

isto é, a magnitude da resposta ao impulso do filtro é igual a do codificador revertida no tempo e independente da forma de onda do sinal. Para garantir que os sinais não interfiram coerentemente na saída do decodificador, deve-se assegurar que os atrasos relativos entre o codificador e o decodificador estejam descasados de um valor maior que o tempo de coerência do canal [1]; daí a aproximação denotada em (4).

\subsection{RUÍDO DE BATIMENTO ÓPTICO}

Geralmente, os esquemas CDMA em RF se baseiam na detecção linear da envoltória dos sinais de entrada após a mixagem com uma réplica do código armazenado no receptor. O ganho de processamento fica limitado, em relação ao máximo 
teórico, tipicamente, pelo vazamento (crosstalk) causado pela ortogonalidade imperfeita entre as seqüencias, representada matematicamente através de correlações cruzadas não nulas. De forma distinta, os esquemas fotônicos utilizam meios de detecção óptica com lei quadrática, nos quais todos os campos incidentes são misturados. Os produtos de mixagem (batimento) resultantes, ausentes nos sistemas de RF, geram um ruído elétrico em banda-base se os campos ocuparem, aproximadamente, a mesma largura de faixa óptica. Esse tipo de ruído pode limitar severamente o desempenho dos sistemas CDMA fotônicos porque o mesmo tende a crescer com o quadrado do número de usuários, enquanto que a correlação total entre os códigos aumenta linearmente com o mesmo fator. Assim, apesar da obtenção de códigos de baixa correlação cruzada ser um pré-requisito em CDMA óptico, adicionalmente, o ruído de batimento tem que ser mantido em níveis aceitáveis [1].

As estratégias para a redução do ruído de batimento incluem a utilização de fontes de luz com largura de faixa relativamente grandes, de modo a reduzir a incidência do batimento dentro da banda passante do receptor, o emprego de técnicas de detecção diferencial e, principalmente, o uso de portas de transmissão óptica temporizadas. Essa última técnica é descrita, resumidamente, na próxima subseção.

\subsection{PORTA DE TRANSMISSÃO TEMPORIZADA}

Muitos esquemas CDMA fotônicos utilizam pulsos luminosos estreitos e são baseados no conceito de espalhamento temporal. Nessas configurações. os dados são transmitidos através de um pulso muito menor que o intervalo de bit e é convertido (espalhado) por um codificador em uma seqüência de chips de alta freqüência e baixa intensidade. O processo de decodificação casada concentra o sinal, reconstruindo o pulso original, enquanto que os sinais descorrelacionados são mantidos espalhados temporalmente. Para um dado período de bit, a informação proveniente do transmissor selecionado estará concentrada, idealmente, em um único intervalo de chip $T_{c}$, contendo o pulso reconstruído, enquanto que o ruído de interferência de múltiplo acesso se encontrará espalhado aleatoriamente em todo o intervalo de bit $T$. A discriminação do sinal pode ser obtida por meio da comparação do pulso reconstituído com um nível de limiar de decisão adequado. $\mathrm{O}$ processo de detecção pode ser aprimorado através de uma porta de transmissão que é aberta, apenas, naqueles intervalos de chip ativos da sequiência de origem, codificada para cada bit e, assim, os sinais incidentes fora dos intervalos de transmissão serão rejeitados. Logo, a porta de transmissão temporizada se comporta de forma análoga a um filtro passafaixa sobre o sinal espalhado espectralmente [1].

A melhoria na relação sinal-ruído após a aplicação da técnica descrita acima é dada pela razão entre o período de bit e o intervalo total da janela $\frac{T}{K T_{S}}$, onde $K$ é o número de chips em que a porta encontra-se aberta. Essa técnica é efetiva na redução de qualquer tipo de ruído ou interferência incidindo sobre o sinal recebido, incluindo os casos de ruído balístico, ruído de batimento e crosstalk. Em princípio, a porta de transmissão pode ser posicionada antes ou depois do fotodetetor, sem afetar o ganho de processamento. Entretanto,

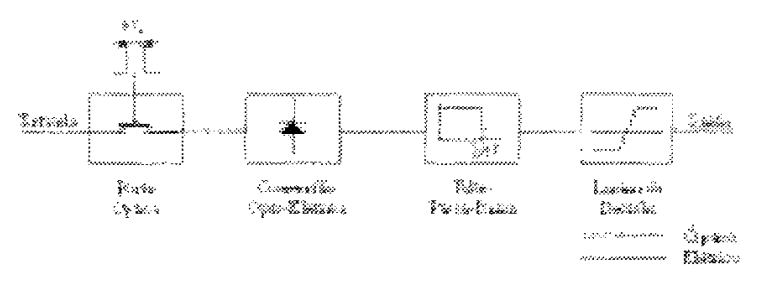

Figura 2. Receptor com porta de transmissão óptica.

posicionando-a antes do detetor, como ilustrado na Fig. 2, tem a vantagem de reduzir a largura de faixa mínima do detetor de $\frac{1}{2 T_{c}}$ para $\frac{1}{2 T}$. Em contrapartida, a contenção da banda do detetor dificulta a adoção da técnica de detecção por limitação abrupta, a menos que a porta de transmissão exerça, também, a função limitadora. Esse método alternativo de detecção não-coerente, descrito em detalhes na próxima seção, é capaz de fornecer um desempenho superior em relação à técnica de reconstrução direta dos pulsos de transmissão descrita anteriormente.

\section{DETECÇÃO NÃO-COERENTE DE SI- NAIS UNIPOLARES}

Os esquemas de codificação para sistemas CDMA ópticos não coerentes apresentam uma característica diversa e essencial: as seqüências devem ser adequadas para sinalização unipolar, pois. a amplitude dos pulsos fotônicos transmitidos pelos usuários é sempre positiva. Apesar da utilização de códigos bipolares ter sido também proposta em sistemas utilizando dois canais ópticos simultaneamente [5], o presente trabalho tem interesse apenas no caso exclusivamente unipolar.

\subsection{SINALIZAÇÃO BINÁRIA UNIPOLAR}

Em um sistema de transmissão unipolar, as formas de onda dos sinais podem assumir apenas amplitudes positivas e, em decorrência, o nível médio dos sinais não é nulo. Considerando o caso de sinalização binária, admite-se que cada usuário disponha de dois símbolos distintos, representando os bits zero e um, tal que

$$
s_{i}(t) \geq 0 \quad 0 \leq t<T . \quad i=0,1
$$

onde $T$ é o intervalo de bit. Assume-se, ainda, que cada símbolo está associado a uma sequiência unipolar normalizada $\phi_{i}(t)$, composta por um trem de $K$ pulsos (chips) com amplitude unitáría e duração $T_{c}$. conforme ilustrado na Fig. 3. Desse modo, cada período de bit encontra-se dividido em $N$ intervalos (chips), dos quais apenas $K$ chips podem ser ativados durante o símbolo e, portanto, tem-se que

$$
N=\frac{T}{T_{c}}
$$

Em consequiência, o nível médio das formas de onda normalizadas será dado por

$$
\mu=\frac{1}{T} \int_{0}^{T} \phi_{i}(t) d t=\frac{K}{N^{\top}}
$$




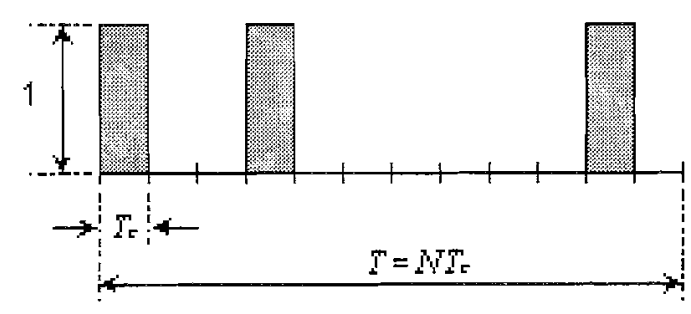

Figura 3. Exemplo de seqüência unipolar normalizada de comprimento $N=12$ e $\mathrm{K}^{-}=3$ chips ativos.

Portanto, pode-se interpretar que cada um dos sinais o, $(t)$ ocupa $K$ dimensões de um espaço $N$-dimensional, cuja base ortonormal pode ser representada por $N$ pulsos distintos $\Psi_{n}(t)$ de amplitude unitária e duração $T_{c}$, isto é,

$$
\Psi_{n}(t)=\left\{\begin{array}{cc}
1 & (n-1) T_{c} \leq t<n T_{c} \\
0 & \text { fora }
\end{array}\right.
$$

e $n=1 . \cdots . N$. Assim, os sinais podem ser representados como pontos em uma hiperesfera, gerados por meio de uma combinação linear dos vetores da base do espaço, de modo que

$$
s_{i}(t)=A \phi_{i}(t)=A \sum_{n=1}^{N} a_{i n} \Psi_{n}(t)
$$

onde a seqüência de $N^{\top}$ coeficientes $\left\{a_{i n}\right\}$ é escolhida de acordo com as regras de construção do código unipolar utilizado no sistema, porém, com a seguinte característica em comum: as seqüências possuem $K$ coeficientes de amplitude unitária, enquanto que os demais $N^{\top}-K$ coeficientes têm amplitude nula. Em decorrência, os sinais apresentam valor médio diferente de zero, isto é,

$$
\overline{s_{i}(t)}=\mu A=\frac{K A}{N}
$$

e potência dada por

$$
\overline{s_{i}^{2}(t)}=\frac{1}{T} \int_{0}^{T} s_{i}^{2}(t) d t=\mu A^{2}=\frac{K A^{2}}{N}
$$

Logo, a energia contida nos sinais, durante um intervalo de símbolo, é constante, e pode ser calculada através de

$$
E_{s}=\overline{s_{i}^{2}(t)} T=K A^{2} T_{c}
$$

Com as restrições impostas, existem duas maneiras básicas para se efetuar a sinalização binária em um canal unipolar: podal e ortogonal. A sinalização podal consiste na transmissão de uma forma de onda toda nula no caso de um bit zero, e ativando-se o trem de pulsos no caso em que o bit é um, isto é,

$$
s_{i}(t)=b_{i} A \phi_{1}(t)=\left\{\begin{array}{cc}
0 & b_{0}=0 \\
A \sum_{n} a_{1 n} \Psi_{n}(t) & b_{1}=1
\end{array}\right.
$$

A outra alternativa consiste em se enviar duas formas de onda distintas e ortogonais, selecionadas de acordo com o nível lógico do bit a ser transmitido, tal que

$$
\begin{aligned}
s_{i}(t) & =\left(1-b_{i}\right) A o_{0}(t)+b_{i} A \phi_{1}(t) \\
& = \begin{cases}A \sum_{n} a_{0 n} \Psi_{n}(t) & b_{0}=0 \\
A \sum_{n} a_{1 n} \Psi_{n}(t) & b_{1}=1\end{cases}
\end{aligned}
$$

e em ambos os casos tem-se que

$$
s_{0}(t) s_{1}(t)=0
$$

A Fig. 4 mostra um exemplo de duas formas de onda unipolares e ortogonais típicas, adequadas para sistemas CDMA fotônicos. Observa-se que para satisfazer (15), é necessário que os chips ativos das seqüências $\left\{a_{0 j}\right\}$ e $\left\{a_{1 k}\right\}$ ocorram em instantes diferentes, ou seja, para $j \neq h$. Como conseqüência das restrições impostas, as estatísticas dessas sequiências podem ser computadas, independentemente do modo como as mesmas são ordenadas. Assim, tem-se que o valor médio e a média quadrática dos coeficientes das seqüências não nulas são dadas, respectivamente, por

$$
\begin{aligned}
& \overline{a_{i n}}=\frac{1}{N} \sum_{n=1}^{N} a_{i n}=\frac{K}{N} \\
& \overline{a_{i n}^{2}}=\frac{1}{N} \sum_{n=1}^{N} a_{i n}^{2}=\frac{K}{N}
\end{aligned}
$$

Além disso, devido a ortogonalidade dos símbolos pertencentes a um dado usuário, pode-se escrever que

$$
\overline{a_{0 n} a_{1 n}}=\frac{1}{N} \sum_{n=1}^{N} a_{0 n} a_{1 n}=0
$$

Entretanto. a autocorrelação dos coeficientes das sequiências não pode ser determinada previamente, pois, a mesma depende das características intrínsecas do código gerador. Porém, para uma seqüência unipolar, o seu valor será diferente de zero obrigatoriamente. Assim, na ausência dos detalhes de construção do código, apenas pode-se afirmar que

$$
\overline{a_{i j} a_{i k}}=\left\{\begin{array}{cc}
\frac{K}{N} & j=k \\
\frac{\eta}{N} & \text { caso contrário }
\end{array}\right.
$$

onde $\eta \leq K$ é o número médio de chips ativos coincidentes entre a seqüência original e a sua versão deslocada ciclicamente.

\subsection{DETECÇÃO CONVENCIONAL}

A Fig. 5 mostra a estrutura dos receptores para os dois tipos de sinalização unipolar. A regra de decisão a ser adotada no caso de sinalização ortogonal consiste, simplesmente, em comparar as saídas do correlatores e decidir por aquela que apresenta o maior valor ao final de cada intervalo de bit. Já no caso de sinalização podal, utiliza-se apenas um contelator, e a decisão pode ser efetuada comparando-se a sua saída com um nível de limiar $z_{\gamma}$. O sinal de interferência pode ser representado no espaço $N$-dimensional através de

$$
w(t)=\sum_{n=1}^{N} w_{n} \Psi_{n}(t)
$$




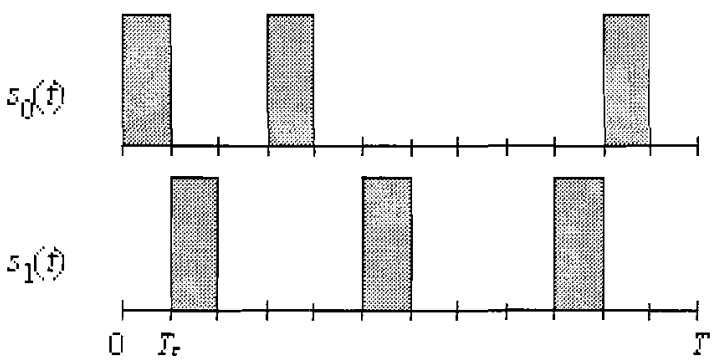

Figura 4. Exemplo de sequiencias unipolares ortogonais $\left(K=3\right.$ e $\left.\lambda^{-}=12\right)$.

notando que como $w_{n} \geq 0$, o nível médio de interferência não é nulo, ou seja, $\bar{u} \geq 0$, e a energia total interferente é dada por

$$
\begin{aligned}
E_{u}=\int_{0}^{T} u^{2}(t) d t & =T_{c} \sum_{n=1}^{N} u_{n}^{2} \\
& =E_{u_{C}}+E_{w_{A}}
\end{aligned}
$$

onde $E_{u_{c}}$, e $E_{u^{*}-1}$ são respectivamente as parcelas da energia geradas pela componente $\mathrm{DC}$ e pela componente $\mathrm{AC}$ do sinal de interferência, isto é,

$$
\begin{aligned}
& E_{w_{C}}=\bar{w}^{2} T \\
& E_{w_{A}}=\sigma_{u}^{2} T
\end{aligned}
$$

onde $\sigma_{u}^{2}$ representa a variância da interferência.

$\mathrm{Na}$ entrada do receptor, o sinal de interesse encontra-se combinado à interferência causada pelos demais usuários que compartilham o canal de transmissão, isto é,

$$
r(t)=s_{j}(t)+u(t)
$$

e é correlacionado com as réplicas sincronizadas dos dois símbolos que podem ter sido transmitidos, $s_{0}(t)$ e $s_{1}(t)$. Assim, ao final dos intervalos de bit. na saída de cada correlator obtém-se que

$$
z_{i}=\int_{0}^{T} r(t) s_{i}(t) d t=T_{c} \sum_{n=1}^{N}\left(a_{i n} a_{j n} A^{2}+a_{i n} w_{n} A\right)
$$

Considerando que os bits são equiprováveis e assumindo que $a_{i n}$ e $u_{n}$ são independentes, então, os valores esperados na saída de um dos correlatores podem ser calculados por

$$
\begin{aligned}
E\left(z_{1} \mid s_{1}\right) & =A^{2} T_{c} \sum_{n=1}^{N} \overline{a_{1 n}^{2}}+A T_{c} \bar{u} \sum_{n=1}^{N} \overline{a_{1 n}} \\
& =K A I_{c}(A+\bar{u})=E_{s}\left(1+\frac{\bar{u}}{A}\right) \\
E\left(z_{1} \mid s_{0}\right) & =A^{2} I_{c} \sum_{n=1}^{N} \overline{a_{0 n} a_{1 n}}+A T_{c} \bar{u} \sum_{n=1}^{N} \overline{a_{1 n}} \\
& =K A T_{c} \bar{u}=E_{s} \frac{\bar{u}}{A}
\end{aligned}
$$

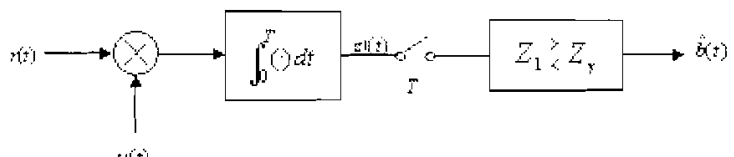

(a)

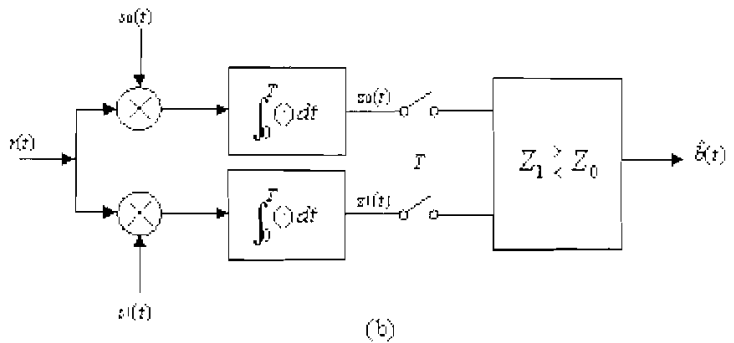

6

Figura 5. Estrutura dos receptores para sistemas unipolares: (a) sinalização podal (b) sinalização ortogonal.

Além disso, a variância na saída de um correlator em particular pode ser obtida, aplicando-se a definição de variância sobre cada um dos termos de (23)

$$
\begin{aligned}
\operatorname{var}\left(z_{1} \mid s_{m}\right) & =\operatorname{var}\left(A^{2} T_{c} \sum_{n=1}^{N} a_{1 n} a_{m n} \mid s_{n}\right) \\
& +\operatorname{var}\left(A T_{c} \sum_{n=1}^{N} a_{1 n} w_{n}\right) \\
& =\operatorname{var}\left(X_{1} \mid s_{n}\right)+\operatorname{var}(Y)
\end{aligned}
$$

Desenvolvendo a primeira parcela de (25) para cada símbolo de entrada. obtém-se que

$$
\begin{aligned}
\operatorname{var}\left(X_{1} \mid \bar{s}_{1}\right) & =\operatorname{var}\left(A^{2} T_{c} \sum_{n=1}^{N} a_{1 n}^{2}\right) \\
& =\operatorname{var}\left(K A^{2} T_{c}\right)=0 \\
\operatorname{var}\left(X_{1} \mid s_{0}\right) & =\operatorname{var}\left(A^{2} T_{c} \sum_{n=1}^{N} a_{0 n} a_{1 n}\right)=0
\end{aligned}
$$

Assim, conclui-se que devido as seqüências do usuário serem ortogonais, essas variâncias condicionais são nulas. não importando se o símbolo recebido corresponde à seqüência particular do correlator ou não. Em consequiência, verifica-se que a potência $\mathrm{AC}$ de interferência, na saída do correlator, independe do símbolo sendo detectado e, portanto. tem-se que 


$$
\begin{aligned}
\sigma_{z_{i}}^{2}=\operatorname{var}\left(z_{i} \mid s_{m}\right) & =\operatorname{var}(Y) . \text { Logo, pode-se escrever que } \\
\sigma_{z_{1}}^{2} & =E\left(A^{2} T_{c} \sum_{j} \sum_{k} a_{1 j} a_{1 k} u_{j} u_{k}\right) \\
& -E^{2}\left(A T_{c} \sum_{j} a_{1 j} u_{j}\right) \\
& =A^{2} T_{c}^{2} \overline{u^{2}} \sum_{j} \overline{a_{1 j}^{2}} \\
& +A^{2} T_{c}^{2} \bar{u}^{2} \sum_{j} \sum_{k \neq j} \overline{a_{1 j} a_{1 k}} \\
& \left(A T_{c} \bar{w} \sum_{j} \overline{a_{1 j}}\right)^{2} \\
& =K A^{2} T_{c}^{2} \overline{u^{2}}+K^{2}\left(K^{-}-1\right) A^{2} T_{c}^{2} \bar{u}^{2} \\
& K^{2} A^{2} T_{c}^{2} \bar{u}^{2} \\
& =K A^{2} T_{c}^{2}\left(\overline{u^{2}}-\bar{u}^{2}\right)
\end{aligned}
$$

Reconhecendo na última igualdade de (27) que a variância da interferência no canal de transmissão é dada por $\sigma_{w}^{2}=$ $\overline{u^{2}}-\bar{u}^{2}$ e, ainda, com auxílio de (6), (12) e (21), finalmente, obtém-se que

$$
\sigma_{z_{1}}^{2}=\frac{E_{s} E_{u_{-1}}}{N}
$$

Comparando-se o resultado em (28) para sinalização unipolar, com o correspondente para o caso bipolar [6], verificase que os mesmos são similares. A variância da interferência na saída do correlator é decorrente do produto entre a energia do símbolo e a parcela da energia de interferência gerada pela componente $\mathrm{AC}$ do sinal interferente, atenuado pelo número de dimensões $N$. No caso unipolar, essa energia de interferência é dada por $E_{w_{A}}=\sigma_{w}^{2} T$, enquanto que no caso bipolar, a componente DC é nula e, portanto, toda energia $E_{u}$. é proveniente, também, da componente $\mathrm{AC}$ da interferência.

\subsubsection{SINALIZAÇÃO ORTOGONAL}

No caso de sinalização ortogonal, a variável aleatória de decisão é constituída a partir da diferença das saídas dos correlatores, isto é, $z=z_{1}-z_{0}$. Em conseqüência, o seu valor esperado, para cada símbolo transmitido, pode ser obtido a partir de (24), resultando que

$$
\begin{aligned}
E\left(z \mid s_{m}\right) & =E\left(z_{1} \mid s_{m}\right)-E\left(z_{0} \mid s_{m}\right) \\
& = \begin{cases}-E_{s} & m=0 \\
+E_{s} & m=1\end{cases}
\end{aligned}
$$

Considerando que a fonte de dados é equiprovável, então, a esperança e a variância do processo estocástico de decisão são obtidas, neste caso, por

$$
\begin{aligned}
\bar{z} & =E\left(z_{1}\right)-E\left(z_{0}\right)=0 \\
\sigma_{z}^{2} & =\sigma_{z_{0}}^{2}+\sigma_{z_{1}}^{2}=2 \sigma_{z_{1}}^{2}
\end{aligned}
$$

Assim, a relação sinal-interferência da variável de decisão pode ser calculada com o auxílio de (28), (29) e (30), obtendo-se que

$$
(S / J)_{o}=\sum_{i=0}^{1} \frac{E^{2}\left(z_{i} \mid s_{i}\right)}{\operatorname{var}\left(z_{i} \mid s_{i}\right)} p\left(s_{i}\right)=\frac{N^{-} E_{s}}{2 E_{w_{A}}}
$$

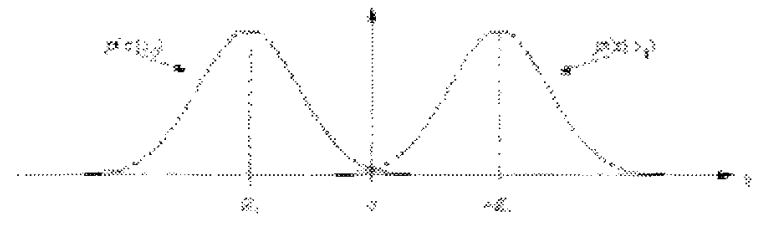

Figura 6. Funções densidade de probabilidade condicionais da variável de decisão para o caso de sinalização ortogonal.

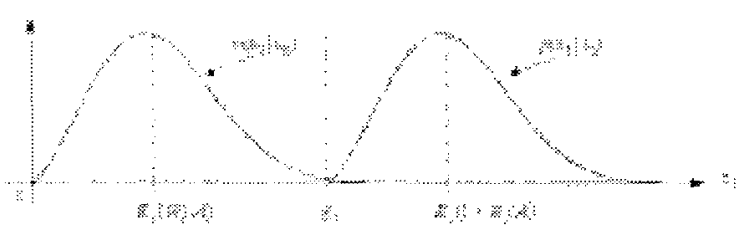

Figura 7. Funções densidade de probabilidade condicionais na saída do correlator para o caso de sinalização podal.

A Fig. 6 ilustra as funções densidade de probabilidade condicionais $p\left(z \mid s_{0}\right)$ e $p\left(z \mid s_{1}\right)$ para o caso de sinalização ortogonal. Devido à disposição simétrica das mesmas em torno da origem, o limiar de decisão deve ser escolhido como $z_{\gamma}=0$. Logo, a probabilidade de erro de bit. nesse caso, será dada por

$$
\begin{aligned}
P_{b_{0}} & =P\left(z>0 \mid s_{0}\right) p\left(s_{0}\right)+P\left(z<0 \mid s_{1}\right) p\left(s_{1}\right) \\
& =\int_{0}^{\infty} p\left(z \mid s_{0}\right) d z=\int_{-\infty}^{0} p\left(z \mid s_{1}\right) d z
\end{aligned}
$$

onde devido a simetria do canal, pode-se escrever a última equação.

\subsubsection{SINALIZAÇÃO PODAL}

No caso de sinalização podal, a decisão é realizada por meio do sinal de saída do único correlator do receptor $z_{1}$, comparado ao limiar de decisão $z_{7}$. A partir de (24), verificase que a variável aleatória na saída do correlator, apresenta média global, ao longo do tempo, não nula. A Fig. 7 ilustra as funções densidade de probabilidade condicionais $p\left(z_{1} \mid s_{0}\right)$ e $p\left(z_{1} \mid s_{1}\right)$ para o caso de sinalização podal. Observa-se que devido a natureza puramente aditiva da interferência no canal unipolar, essas funções são assimétricas, acarretando que

$$
\int_{-\infty}^{0} p\left(z_{1} \mid s_{0}\right) d z_{1}=\int_{-\infty}^{E_{s}} p\left(z_{1} \mid s_{1}\right) d z_{1}=0
$$

Logo, o limiar de decisão deve ser adotado de maneira que $z_{\gamma} \geq E_{s}$. No entanto, a obtenção de um valor de limiar ótimo requer, além do conhecimento completo da distribuição de probabilidade da interferência, que o receptor estime, também, o seu nível médio, de modo a minimizar a probabilidade de erro média, isto é, computando-se

$$
\min _{z_{\alpha_{1}}}\left\{p\left(s_{0}\right) \int_{\tilde{z}_{\gamma_{1}}}^{\infty} p\left(z_{1} \mid s_{0}\right) d z_{1}+p\left(s_{1}\right) \int_{-\infty}^{z_{\gamma_{2}}} p\left(z_{1} \mid s_{1}\right) d z_{1}\right\}
$$




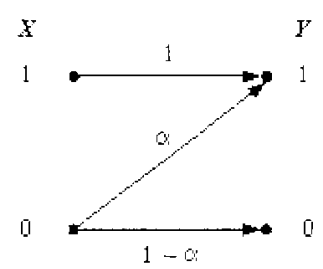

Figura 8. O Canal Z.

Porém, uma regra de decisão sub-ótima pode ser prontamente estabelecida, fazendo-se $z_{\urcorner}=E_{s}$. Nesse caso, os valores esperados para a variável de decisão $z=z_{1}-z_{\text {, }}$ serão expressos por

$$
E\left(z \mid s_{m}\right)=E\left(z_{1} \mid s_{m}\right)-E_{s}=\left\{\begin{array}{cc}
-E_{s}\left(1-\frac{\bar{u}}{A}\right) & m=0 \\
E_{s} \frac{\bar{u}}{A} & m=1
\end{array}\right.
$$

Assim, a probabilidade de erro de bit resultante será dada por

$$
\begin{aligned}
P_{b_{p}} & =P\left(z_{1}>E_{s} \mid s_{0}\right) p\left(s_{0}\right)+P\left(z_{1}<E_{s} \mid s_{1}\right) p\left(s_{1}\right) \\
& =\frac{1}{2} \int_{E_{s}}^{\infty} p\left(z \mid s_{0}\right) d z
\end{aligned}
$$

onde de acordo com (33), usou-se que a segunda parcela da expressão anterior é nula.

Portanto. essa configuração origina um canal binário totalmente assimétrico, denominado canal $Z$, pois não há possibilidade de erro na detecção de bits transmitidos através do canal com nível lógico igual a um, conforme mostrado na Fig. 8. Além disso, a relação sinal-interferência pode ser definida, nesse caso, por meio de

$$
(S / J)_{p}=\frac{E^{2}\left(z \mid s_{0}\right)}{\operatorname{var}\left(z \mid s_{0}\right)}=\frac{N E_{s}}{E_{w_{A}}}\left(1-\frac{\overline{u^{\prime}}}{A}\right)^{2}
$$

Comparando-se as expressões (31) e (37), verifica-se que, para potências de interferência $\mathrm{AC}$ idênticas, um sistema utilizando sinalização ortogonal é afetado, em princípio, duas vezes mais em relação a outro com sinalização podal. No entanto, para este último, a energia útil do sinal diminui quadraticamente com o nível médio da interferência. Logo, não é possível prever, a priori, qual dos sistemas é mais vantajoso, sem que se conheça as características da interferência a qual os mesmos serão submetidos.

\subsubsection{DETECÇÃO CONVENCIONAL EM SISTE- MAS CDMA}

Considerando um sistema CDMA em um canal unipolar, compartilhado por $M$ usuários no total, pode-se determinar a variância da interferência para cada um dos tipos de sinalização. A variância do sinal transmitido devido a cada um dos usuários concorrentes é expressa por

$$
\sigma_{s}^{2}=\left[\overline{s_{1}^{2}(t)}-{\overline{s_{1}(t)}}^{2}\right] p\left(s_{1}\right)+\left[\overline{s_{2}^{2}(t)}-{\overline{s_{2}(t)}}^{2}\right] p\left(s_{2}\right)
$$

Logo, assumindo que a fonte é equiprovável, tem-se que a variância do sinal de cada interferente, nos casos de sinalização ortogonal e podal é dada, respectivamente, por

$$
\begin{aligned}
& \sigma_{s_{0}}^{2}=\frac{K A^{2}}{N}-\frac{K^{2} A^{2}}{N^{2}}=\frac{E_{s}}{T}\left(1-\frac{K}{N}\right) \\
& \sigma_{s_{p}}^{2}=\frac{1}{2}\left(\frac{K A^{2}}{N}-\frac{K^{2} A^{2}}{N^{2}}\right)=\frac{E_{s}}{2 T}\left(1-\frac{K}{N}\right)
\end{aligned}
$$

Assim, admitindo que os sinais interferentes são estatisticamente independentes, obtém-se que a energia decorrente da parcela $\mathrm{AC}$ da interferência, resultante da ação conjunta de $M-1$ usuários concorrentes, é expressa em cada um dos casos. respectivamente, por

$$
\begin{aligned}
& E_{u_{w_{p}}}=(M-1) \sigma_{s_{p}}^{2} T=(M-1)\left(1-\frac{K}{N}\right) E_{s} \\
& E_{u_{p}, p}=(M-1) \sigma_{s_{p}}^{2} T=\frac{M-1}{2}\left(1-\frac{K}{N}\right) E_{s}
\end{aligned}
$$

Observa-se a partir das expressões anteriores que a energia interferente diminui com o incremento do número de chips ativos. Entretanto, deve-se ressaltar que no primeiro caso, para que se mantenha a ortogonalidade entre os símbolos, é necessário que $K \leq N / 2$. Então, para sinalização ortogonal, a relação sinal-interferência pode ser obtida a partir de (31), resultando que

$$
(S / J)_{o}=\frac{N}{2(M-1)\left(1-\frac{K}{N}\right)}
$$

e de acordo com (1), pode-se concluir que o ganho de processamento, nesse caso, é dado por

$$
G_{P_{o}}=\frac{N}{2\left(1-\frac{K}{N}\right)}
$$

Logo, como conseqüência dos resultados obtidos em (41) e (42), o desempenho do sistema pode ser maximizado ao se utilizar códigos com o maior número possível de chips ativos por bit, isto é, fazendo-se $K=N / 2$. Com essa condição e as demais restrições impostas anteriormente, então, um sistema CDMA com sinalização ortogonal poderia atingir um ganho de processamento máximo da ordem da dimensão do espaço de sinais, ou seja, $G_{P_{0}}(\max )=N$.

Uma conseqüência importante, advinda do resultado anterior, é que o desempenho previsto para um sistema CDMA unipolar com sinalização ortogonal e detecção convencional, é equivalente ao dos sistemas com sinalização antipodal em canais bipolares. Além disso, pode-se concluir que, em princípio, é possível utilizar as mesmas seqüências de espalhamento tradicionais (p. ex., Gold, Kasami, etc.), apenas que deve-se ter o cuidado de mapeá-las adequadamente, isto é, transmitindo-se um dos símbolos com os chips ativos da seqüência original, e o outro com esses mantidos em zero e os demais sendo, agora, ativados. Além disso, caso as seqüências originais apresentem um comprimento ímpar, devese manter um dos chips em excesso sempre desativado. 
Para um sistema CDMA com sinalização podal, o nível médio da interferência pode ser obtido a partir de (10), e observando-se que

$$
\overline{u^{\prime}}=p\left(s_{1}\right)(M-1) \overline{s_{1}(t)}=\frac{M(M-1) A}{2 Y^{-}}
$$

onde assumiu-se que $p\left(s_{1}\right)=1 / 2$. Então, em decorrência de (37) e (40), a relação sinal-interferência para esse sistema pode ser calculada por

$$
\begin{aligned}
(S / J)_{p} & =\frac{2 N\left[1-\frac{K(M-1)}{2 \Lambda}\right]^{2}}{(M-1)\left(1-\frac{K}{N}\right)} \\
& =\frac{[2 N-M(M-1)]^{2}}{2(M-1)(M-K)}
\end{aligned}
$$

sendo essa expressão válida desde que $K \leq \frac{2 N}{M-1}$. Assim, o ganho de processamento, nesse caso, pode ser escrito como

$$
G_{P_{p}}=\frac{[2 N-K(M-1)]^{2}}{2(N-K)}
$$

Analisando a expressão anterior, determina-se que o ganho de processamento atinge o valor máximo para $K=1$, resultando que

$$
G_{P_{p}}(\max )=\frac{(2 N-M+1)^{2}}{2 N-2}
$$

sendo, portanto, dependente do número de usuários que compartilham o canal. O ganho de processamento diminui a partir de um ganho máximo igual a $2 N$ aproximadamente, quando há apenas um usuário interferente no canal $(M=2)$, e torna-se menor que o caso ortogonal para uma relação $M / N \simeq(2-\sqrt{2}) \simeq 0,59$, desde que $N \gg 1$. Assim, apesar do ganho de processamento no caso de sinalização podal ser maior para um número de usuários típico, não é possível afirmar que esta conduza a um desempenho superior, devido ao fato que os ganhos máximos, em cada caso, são obtidos para valores de $K$ radicalmente diferentes e, portanto, gerando distribuições de probabilidade distintas para a variável de decisão. De fato, os resultados obtidos através de simulação, mostrados na Fig. 9, para o caso bit e chip síncrono e seqüências aleatórias, indica que o desempenho da sinalização ortogonal é superior quando se utiliza um código que minimiza a variância da interferência, isto é, para $K=N / 2$. Além disso, verifica-se que a probabilidade de erro para sinalização podal apresenta um ponto de mínimo para $K>1$.

\subsection{DETECÇÃO POR LIMITAÇÃO ABRUPTA}

$\mathrm{Na}$ subseção anterior verificou-se que um sistema CDMA utilizando sinalização podal sofre forte influência do nível médio de interferência presente no canal. Um artifício possível para reduzir esse efeito, consiste na utilização de um elemento limitador de intensidade, não linear, no caminho do sinal [7]. Um limitador ideal é definido como

$$
g(x)=\left\{\begin{array}{cc}
A & x \geq A \\
0 & 0 \leq x<A
\end{array}\right.
$$

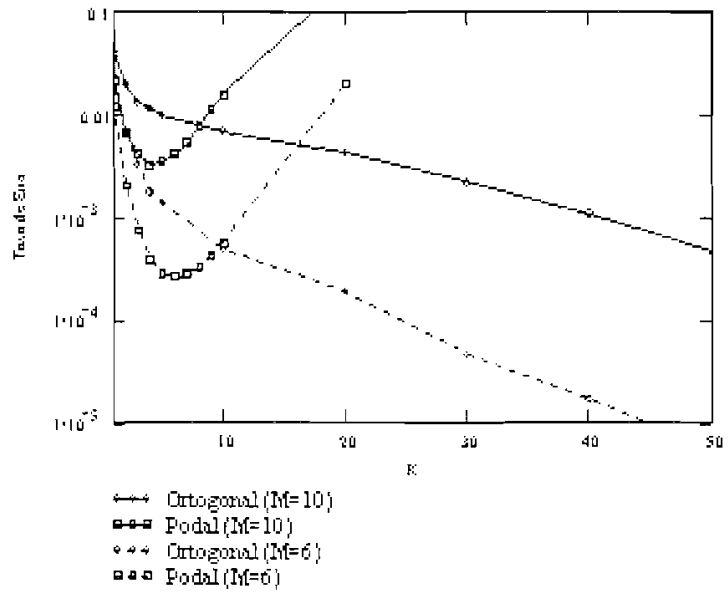

Figura 9. Taxa de erro de bit para detecção convencional das sinalizações podal e ortogonal. Resultados de simulação de um sistema CDMA para 6 e 10 usuários bit e chip síncronos $(N=100)$.

Assim, se a intensidade do sinal for maior ou igual que a amplitude de um pulso isolado, o dispositivo limita a intensidade naquele valor, caso contrário, a saída obtida será nula. O processo de limitação abrupta melhora o desempenho dos sistemas com sinalização podal porque impede que diversos padrões de interferência. com chips excessivamente atingidos, causem erros na detecção. Por exemplo, considerando uma amplitude normalizada $A=1$, e um número de chips ativos por bit $K=3$, todos os padrões de interferência $I_{1}=\{1.1,1\}, I_{2}=\{2.1,0\}$ e $I_{3}=\{3.0 .0\}$ resultariam em valor igual a 3 na saída do correlator (ou filtro casado) de um detetor convencional, causando um erro, caso o bit transmitido fosse igual a zero. Entretanto, ao utilizar-se limitação abrupta, os padrões seriam modificados pelo dispositivo para $I_{1}^{\prime}=\{1,1,1\}, I_{2}^{\prime}=\{1.1,0\}$ e $I_{3}^{\prime}=\{1,0,0\}$. Portanto, as saidas correspondentes do correlator assumiriam os valores 3,2 e 1 , respectivamente. Assim, apenas o padrão $I_{1}$ poderia causar um erro de bit na detecção. Uma outra interpretação do benefício do limitador pode ser compreendida, notando-se que o nível médio da interferência entregue ao correlator torna-se menor, ampliando a excursão útil na saída do mesmo.

Outro aspecto pertinente dessa configuração é que a ação do limitador equivale a se efetuar a decisão abrupta do estado de cada chip no receptor, isto é, um modo alternativo de se implementar esta técnica consiste na utilização de um banco de $K$ correlatores sincronizados com a seqüência do transmissor, e cada correlator detectando o estado de um determinado chip alocado na seqüência. A saída de cada correlator é comparada com um nível de limiar igual a energia de chip, isto é, $V_{\gamma}=E_{c}=A^{2} T_{c}$, e a decisão é por um bit um se, e somente se, todas as saídas dos correlatores atingirem esse patamar. Assim, essa técnica vale-se do ganho de codificação correspondente a um código de repetição, com regra de decisão por unanimidade.

Nesse caso, a relação sinal-interferência a que cada chip é submetido pode ser obtida a partir do desenvolvimento efe 
tuado anteriormente para o caso de sinalização podal, apenas. considerando-se que a energia detectada corresponde a um intervalo de chip ativo e, portanto, tem-se que

$$
E_{c}=\frac{E_{s}}{h}
$$

Logo,

$$
\begin{aligned}
(S / J)_{L} & =\frac{E^{2}\left(z \mid s_{0}\right)}{\operatorname{var}\left(z \mid s_{0}\right)}=\frac{\Lambda^{\top} E_{c}^{2}}{E_{c} E_{u_{-1}}}\left(1-\frac{\bar{u}}{A}\right)^{2} \\
& ==\frac{\Lambda_{s}}{K^{2} E_{w_{-1}}}\left(1-\frac{\bar{u}}{A}\right)^{2}
\end{aligned}
$$

Assim, a relação sinal-interferência na saída de cada correlator é reduzida por um fator igual ao número de marcas do código em relação ao caso de detecção convencional, expressa em (37). No entanto, como um erro de bit só ocorre se o bit recebido for zero e se a energia interferente em cada um dos $K$ chips alocados na seqüência do usuário for maior ou igual a $E_{c}$, então a probabilidade de erro em um detetor com limitação abrupta será dada por

$$
P_{b_{\perp}}=\frac{1}{2}\left[\int_{E_{c}}^{\infty} p\left(z \mid s_{0}\right) d z\right]^{K}
$$

Portanto, apesar da degradação na relação sinalinterferência imposta pela técnica de limitação abrupta, é possível que o resultado da integral em (50) seja pequeno o suficiente para fornecer uma probabilidade de erro menor que no caso convencional, para algum valor de $K$. A investigação desse resultado é o tema da próxima seção.

\section{CÓDIGOS UNIPOLARES PARA APLI- CAÇÃO EM CDMA ÓPTICO}

Uma classe de códigos específicos para CDMA óptico foi proposta por Salehi e outros [7]-[10], conhecidos como Códigos Ópticos Ortogonais - OOC, estabelecendo uma sequiência de assinatura para cada usuário, composta de $F$ intervalos (chips), cujas amplitudes podem ser zero ou um. A seqüência de cada usuário é estabelecida pela alocação estática de $h$ chips dentre os $F$ chips disponíveis. Cada bit de informação é transmitido ativando-se todos os $K$ chips se este for igual a um, ou enviando-se uma seqüência toda nula quando o bit é zero. Os códigos OOC apresentam boas propriedades de autocorrelação e correlação cruzada: a autocorrelação cíclica de qualquer sequiência, com deslocamento relativo diferente de zero, e a correlação cruzada cíclica entre duas seqüências quaisquer não excedem um valor inteiro $\lambda$. Quando $\lambda=1$, o código resultante é ótimo no sentido que nenhum outro conjunto de seqüências unipolares de comprimento $F$ e peso $K$ fornece uma probabilidade de erro menor [8]. Entretanto, o $\lambda_{1}$-OOC apresenta uma séria deficiência no número de seqüências distintas que é possível se obter, limitando o número de usuários a

$$
M(\lambda=1) \leq\left\lfloor\frac{F-1}{K(K-1)}\right\rfloor
$$

onde $\lfloor x\rfloor$ representa a parte inteira de $x$. De modo a possibilitar um número maior de sequiências distintas, Azizoglu,

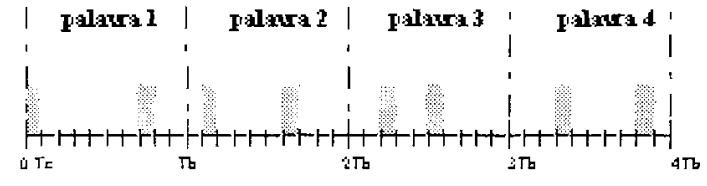

Figura 10. Seqüência OTH $\operatorname{com} F=10, K=2$ e $N=4$

Salehi e Li sugeriram um código $\operatorname{com} \lambda=2$ [10]. Neste caso, o número assinaturas que se pode obter é bem maior

$$
M(\lambda=2) \leq\left\lfloor\frac{(F-1)(F-2)}{K(K-1)(K-2)}\right\rfloor
$$

Assim, por exemplo, para $F=1000$ e $K=8$, existem, no máximo, 17 seqüências distintas para o $\lambda_{1}$-OOC, enquanto que este número cresce para mais de 2900 no caso do $\lambda_{2}$ OOC. Contudo, a penalidade na taxa de erro imposta por este último é severa. Considerando-se 10 usuários para o exemplo anterior, a probabilidade de erro é reduzida de um patamar de $10^{-14}$ para $10^{-8}$, considerando-se que os chips são síncronos e deteção com limitação abrupta em ambos os casos.

\subsection{CÓDIGOS ÓPTICOS COM SALTO TEMPORAL}

Pode-se estruturar um código unipolar estabelecendo-se a assinatura de cada usuário por meio de uma sequiência composta de diversas palavras, cada uma com duração jgual ao intervalo de bit de informação $T$. Além disso, de forma similar aos códigos OOC, cada palavra é dividida em $F$ intervalos de chip de duração $T_{c}$, tal que $T=F T_{c}$ e, para cada palavra, $K$ chips são alocados dinamicamente, sendo que estes serão ativados se o bit a ser transmitido for jgual a um, ou mantidos em zero caso contrário. Assim, a seqüência completa de cada usuário é composta de $N$ palavras distintas, fazendo com que as posições dos chips alocados varie a cada bit transmitido, configurando, portanto, um código óptico com salto temporal (optical time-hopping - OTH) conforme ilustrado na Fig. 10.

\subsubsection{LIMITANTE INFERIOR DA PROBABILIDADE DE ERRO}

Considerando-se inicialmente que $F$ e $N$ são números muito grandes, tendendo a infinito, e que a alocação dos chips é aleatória, obtém-se que a probabilidade de um chip na sequiência ser ativado é dada por

$$
p=\frac{K}{2 F}
$$

onde o fator $1 / 2$ é devido à possibilidade equiprovável de um bit transmitido ser igual a zero.

Em seguida, considerando-se a existência de $M$ usuários ocupando o meio de transmissão e que os chips são síncronos, pode-se determinar a probabilidade que um determinado chip sofra interferência de pelo menos um dos $M-1$ interferentes

$$
P_{c}=1-(1-p)^{M-1}
$$




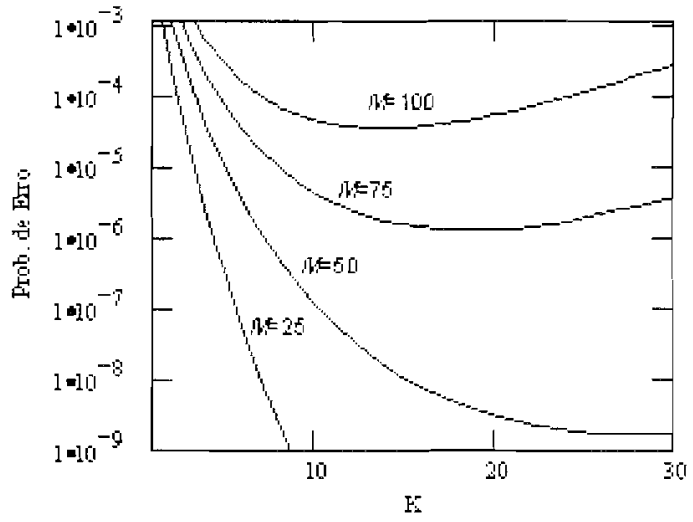

Figura 11. Limitante inferior de desempenho do código OTH com $F=1000$ chips por bit para $25,50,75$ e 100 usuários.

$\mathrm{Na}$ ausência de ruído, supondo que o receptor mantém sincronismo perfeito com o transmissor e o processo de detecção utilize limitação abrupta, a ocorrência de erro em um bit qualquer da sequêencia se dá, apenas, quando o bit transmitido for zero e todos os $K$ chips alocados na palavra em questão sofrerem interferência. Logo, o limitante inferior para a probabilidade de erro de bit para o código OTH pode ser obtido por

$$
P_{i}=\frac{1}{2} P_{c}^{K^{-}}=\frac{1}{2}\left[1-\left(1-\frac{K}{2 F}\right)^{M-1}\right]^{K}
$$

Pode-se constatar a partir da equação acima que as sequiências primas, definidas em [11] e [12] são um caso particular das sequiencias OTH com $K=1$.

A Fig. 11 mostra algumas curvas para o limitante inferior da probabilidade de erro em função do peso do código $K$, para quantidades distintas de usuários. Observa-se que há um peso ótimo para o código, que fornece o melhor desempenho, para cada valor de $M$. Isto decorre do fato que para valores moderados no número de pulsos por bit, a probabilidade de interferência em um chip da seqüência, $P_{c}$, é suficientemente pequena, de modo que o expoente de (55) domina, reduzindo a probabilidade de erro com o aumento de $K$; porém à medida que o peso do código aumenta, a probabilidade de interferência nos chips aumenta paulatinamente, invertendo, por fim, o comportamento da probabilidade de erro.

O peso ótimo do código, $K_{o}$, pode ser computado numericamente para cada par $(M, F)$, ou estimado através do inteiro mais próximo ao resultado da seguinte aproximação, facilmente obtida a partir de (55) para $M \gg 1$

$$
K_{0} \simeq \frac{2 F}{M} \ln 2
$$

Um fato interessante pode ser observado a partir da expressão acima: a probabilidade de um chip ser ativado, quando $K_{o}$ é adotado, tende a

$$
p_{o}=\frac{K_{o}}{2 F} \simeq \frac{\ln 2}{M}
$$

implicando, neste caso, que

$$
\lim _{N \rightarrow \infty} P_{c}=\frac{1}{2}
$$

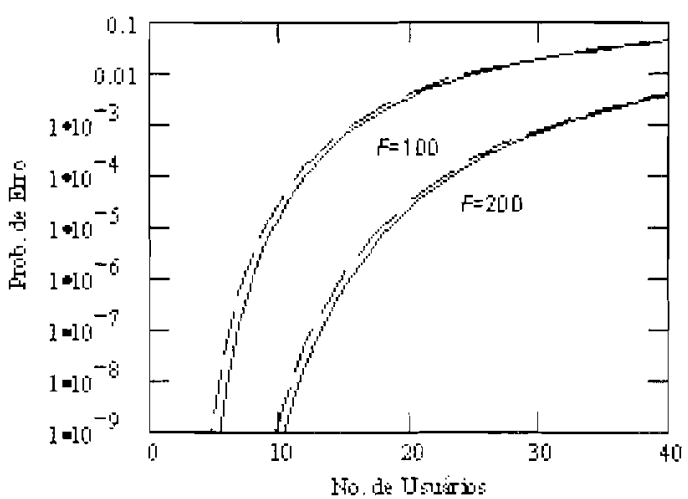

Figura 12. Probabilidade de erro mínima exata e aproximada (curvas tracejadas) para códigos OTH.

Assim, uma estimativa da probabilidade de erro mínima inerente a um código OTH aleatório com deteção por limitação abrupta pode ser obtida substituindo-se (56) e (58) em (55), resultando na expressão abaixo e mostrada na Fig. 12.

$$
P_{0} \simeq \frac{1}{2} \exp \left(-2 \ln ^{2} 2 \frac{F}{M}\right)
$$

\subsubsection{LIMITANTE SUPERIOR DA PROBABILIDADE DE ERRO}

Para se obter um limitante superior para a probabilidade de erro para os códigos OTH, deve-se considerar o pior caso de alinhamento entre as palavras das seqüências interferentes. É um fato conhecido que a taxa de erro é maior quando há sincronismo de chip entre as sequiências [9]. Além disso, a probabilidade de erro aumenta, em certo grau, se as palavras da seqüência são bit síncronas. Este fato pode ser mostrado através do seguinte exemplo. Seja um código OTH $\operatorname{com} F=K=M I=2$. Considerando-se inicialmente o caso bit síncrono, constata-se que ocorrerá erro para um dos usuários se o mesmo transmitir um bit zero e o interferente transmitir um bit um. Logo, a probabilidade de erro neste caso é igual a $P_{s}=1 / 4$. Para o caso assíncrono, o interferente pode estar alinhado na fronteira de bit ou desalinhado com probabilidade $1 / 2$. Se existir alinhamento de bit, a probabilidade de erro será idêntica à computada anteriormente. Caso contrário, um erro somente pode ocorrer se o bit transmitido for zero e os dois bits parcialmente interferentes forem ambos um, resultando numa probabilidade condjegignal de $1 / 8$. Então, a probabilidade de erro total para o caso bit assíncrono resulta em $P_{\alpha}=3 / 16$, portanto, menor que $P_{s}$.

A expressão da probabilidade de erro exata para o código OTH aleatório, bit e chip síncrono, pode ser obtida a partir do teorema a seguir, formulado no contexto destes códigos.

Teorema 1 Para uma sequiencia com peso $K$ e comprimento $F$, seja $p(i, j)$ a probabilidade de que pelo menos $i$ chips selecionados não sejam atingidos, e que pelo menos $j$ chips em posições determinadas sofram interferência, durante um intervalo de bit, causada por $m$ interferentes ativos, chip e bit sincronos. Então, a seguinte igualdade é verdadeira para 


$$
\begin{aligned}
& I_{1}=\{2,2\} \\
& I_{2}=\{3,1\} \\
& I_{1} \cup I_{2}=\{2,1\}
\end{aligned}
$$

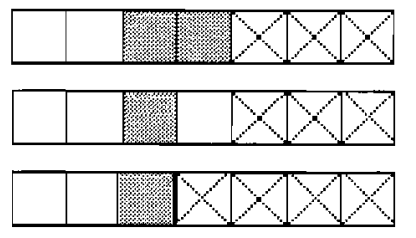

Figura 13. Exemplo de padrões de interferência. As posições em branco representam chips não atingidos, as escuras são as atingidas por pelo menos um interferente e aquelas demarcadas por um " $\mathrm{x}$ " são irrelevantes.

$$
\begin{aligned}
\text { quaisquer } i & \geq 0, j \geq 1 e i+j \leq K \leq F \\
& p(i \cdot j-1)=p(i, j)+p(i+1 \cdot j-1)
\end{aligned}
$$

Prova: Denotando un evento de interferencia cono $I=$ $\{i, j\}$ com probabilidade $p(i, j)$, onde $i$ representa o número mínimo de chips livres de interferência; $j$ o número mínimo de chips que sofrem interferência, produzida em conjunto por $m$ interferentes ativos, tem-se que os $F-i-j$ chips restantes são irrelevantes, isto é, podem ter sido ou não interferidos. Sejam dois eventos de interferência con padrões $I_{1}=\{i \cdot j\}$ $e I_{2}=\{i+1 . j-1\}$, então, todas as permutações de cada um destes padrões de interferência apresenta probabilidade dadas por $p(i . j)$ e $p(i+1 . j-1)$, respectivamente. Considerando, sem perda de generalidade, aquelas permutações em que há coincidência na posição entre $i$ chips não interferidos de ambos eventos, e, simultaneamente, entre $j-1$ chips atingidos, então, sempre existirá uma permutação onde em $I_{1}$ ocorrerá interferência de pelo menos um dos $m$ interferentes e em $I_{2}$ não, numa posição em comum, conforme illustrado na Fig. 13. Assim, como o resultado da união dos eventos é $I_{1} \cup I_{2}=\{i, j-1\}$, conclui-se que a igualdade expressa em (60) é verdadeira.

Corolário 1 A probabilidade de $K$ chips sofrerem interferência em un intervalo de bit, en posições determinadas numa sequiencia de peso $K$, devido a ação de $m$ interferentes ativos é expressa por

$$
p(0 . K)=\sum_{k=0}^{K}(-1)^{k}\left(\begin{array}{c}
K \\
k
\end{array}\right) p(k, 0)
$$

Prova: A partir de (60) pode-se desenvolver a seguinte recorrência

$$
\begin{array}{r}
p(0, K)=p(0, K-1)-p(1 . K-1) \\
=p(0 . K-2)-2 p(1 . K-2) \\
+p(2 . K-2) \\
=p(0 . K-3)-3 p(1 . K-3) \\
+3 p(2 . K-3)-p(3 . K-3) \\
\vdots p(0, K-k)-\left(\begin{array}{c}
K \\
1
\end{array}\right) p(1 . K-k)+\cdots \\
+\cdots(-1)^{k}\left(\begin{array}{c}
K \\
k
\end{array}\right) p(k . K-k)
\end{array}
$$

que conduz diretamente $\grave{a}(61)$, ao fazer-se $k=K$ na igualdade final.

Observa-se a partir de (61) que a probabilidade de erro de bit para um código OTH aleatório de peso $K$, com sincronismo nos intervalos de chip e bit, e submetido ao efeito de $m$ interferentes ativos simultaneamente, $P_{s}(m)=\frac{1}{2} p(0, K)$, só depende da seqüência de probabilidades $p_{k}(m)=p(k, 0)$, cuja única restrição é que pelo menos $k$ chips não sejam atingidos e $k \leq h^{-}$. Estas probabilidades podem ser computadas imediatamente através de

$$
\begin{aligned}
p_{k}(m) & =\frac{\left(\begin{array}{c}
F-k \\
K
\end{array}\right)^{m}}{\left(\begin{array}{c}
F \\
K
\end{array}\right)^{m}} \quad 0 \leq k \leq K \\
& =\prod_{i=0}^{k-1}\left(\frac{F-K-i}{F-i}\right)^{m} \quad 0 \leq k \leq K
\end{aligned}
$$

notando que, quando $k=0$, configura-se o evento certo, isto é, $p_{0}(m)=1$. Desta forma, combinando (61) e (62), obtémse que

$P_{s}(m)=\frac{1}{2}\left[1+\sum_{k=1}^{K}(-1)^{k}\left(\begin{array}{c}K \\ k\end{array}\right) \prod_{i=0}^{k-1}\left(\frac{F-K-i}{F-i}\right)^{m}\right]$

Finalmente, a probabilidade de erro total pode ser obtida, somando-se a contribuição de todos os padrões de bit dos $M-1$ interferentes, isto é

$$
P_{s}=\frac{1}{2^{M-1}} \sum_{m=1}^{M-1}\left(\begin{array}{c}
M-1 \\
m
\end{array}\right) P_{s}(m)
$$

A expressão acima constitui, portanto, um limitante superior para a probabilidade de erro de bit média para os códigos OTH com seqüências aleatórias e bit assíncronas. A Fig. 14 mostra as curvas resultantes para os limitantes superior e inferior, bem como os resultados de simulação do código OTH aleatório com sincronismo apenas de chip.

\subsubsection{CONSTRUÇÃO DE CÓDIGOS OTH}

A concepção das seqüências com salto temporal teve como objetivo maximizar o desempenho, em termos de taxa de erro, para aplicações que requerem códigos unipolares e que utilizem sistema de detecção com limitação abrupta. Códigos como o OOC tiveram como motivador a minimização da autocorrelação e correlação cruzada entre as sequiências, de forma a satisfazer os requisitos de aquisição de sincronismo prioritariamente, reduzindo o número total de sequiências disponíveis.

Para um código OTH com parâmetros $(F, K . N)$, o número de seqüências distintas disponíveis é expressa por

$$
M=\left(\begin{array}{l}
F \\
K
\end{array}\right)^{N}=\left(\frac{F !}{(F-K) ! K !}\right)^{N}
$$




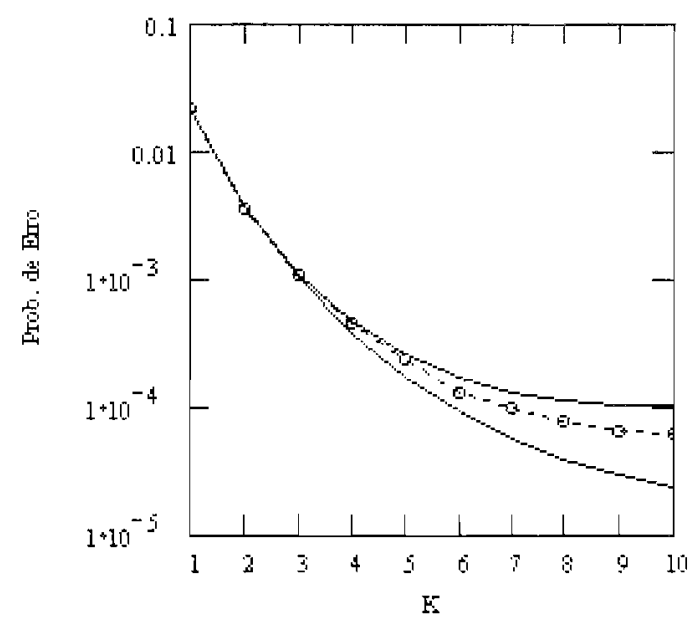

Figura 14. Limitantes superior e inferior da probabilidade de erro para OTH aleatório e resultados de simulação ( $F=100$ e $M=10$ ).

Assim, considerando, por exemplo, $F=100, K=10 \mathrm{e}$ $N=1$, conclui-se a partir de (51). (52) e (65) que o número de sequiências distintas disponíveis, neste caso, são 1 , 13 e $1.7 \times 10^{13}$, para os códigos $\lambda_{1}$-OOC, $\lambda_{2}$-OOC e OTH, respectivamente. Este exemplo ilustra o quanto são raras as seqüências bem comportadas. sob o ponto de vista da correlação cíclica, em meio ao caos dos números.

Sob o aspecto do processo de aquisição de sincronismo, o parâmetro essencial não é, realmente, o valor máximo da autocorrelação para deslocamento relativo diferente de zero $\lambda_{a}$, nem a correlação cruzada máxima entre seqüências $\lambda_{c}$, e sim a relação entre o número total de pulsos da sequêencia e o valor máximo da (auto)correlação. Assim, pode-se definir um fator de mérito de correlação para as seqüências unipolares da forma

$$
Q=K \frac{N}{\lambda}
$$

onde $\lambda$ é o valor máximo da correlação entre sequiências de comprimento $N F$.

Com esta definição, tem-se que para o código $\lambda_{1}$-OOC, $Q_{1}=K$. Então, caso se deseje que um código OTH tenha um desempenho, do ponto de vista de sincronismo, similar ao OOC, poder-se-ia adotar sequiências OTH tais que $\lambda=N$. No entanto, esta igualdade geralmente não é necessária, pois, para minimizar a probabilidade de erro. o sistema deverá estar operando com um código de peso próximo ao ótimo que é, normalmente, bem maior que o peso máximo do OOC, para um dado número de usuários do sistema. Uma estimativa do valor de $\lambda$ para as seqüências OTH em sistemas operando com o peso ótimo obtido em (56), que se aproxima do fator de mérito de um sistema $\lambda_{1}-\mathrm{OOC}$, considerando-se a restrição em (51) e válida para $F>K \gg 1$, pode ser expressa por

$$
\lambda_{0}=\left\lceil 2 \ln 2 \sqrt{\frac{F}{M I}} N\right\rceil
$$

onde $\lceil x\rceil$ representa o menor inteiro maior ou igual a $x$.
Logo. seja qual for o valor adequado para $Q$ a ser adotado, pode-se concluir que o aumento no número de palavras, $\Lambda$, permite o relaxamento da restrição na autocorrelação e correlação cruzada das sequiências, aumentando proporcionalmente o valor de $\lambda$, e com isso, ampliando o número de seqüências que satisfazem o critério, exponencialmente. Este fato pode ser comprovado através do cálculo do número máximo de seqüências com valor de $\lambda$ genérico, obtido a partir do limitante de Johnson para códigos com peso constante [8], adaptada para os códigos OTH

$$
M \leq\left\lfloor\frac{(N F-1)(N F-2) \cdots(N F-\lambda)}{N K(N K-1) \cdots(N K-\lambda)}\right\rfloor
$$

Como $\lambda K=Q \lambda, F>K$ e, geralmente, $Q \gg 1$, então. neste caso, a expressão anterior admite a seguinte simplificaçào

$$
M \leq\left\lfloor\frac{F^{\lambda}}{N K^{\lambda+1}}\right\rfloor
$$

A conclusão é que a escolha adequada do número de palavras das sequiências, permite que se obtenha boas características de autocorrelação e correlação cruzada para as seqüências OTH. Além disso, apesar da probabilidade de erro média destes códigos não depender de $N$, é evidente que o aumento no número de palavras é benéfico, pois, a variância na taxa de erro será reduzida, ao diminuir a incidência de alinhamentos azarados entre as palavras.

\subsection{COMPARAÇÃO DE DESEMPENHO ENTRE CÓDIGOS OTH E OOC}

A probabilidade de erro para um código $\lambda_{1}$-OOC, pode ser derivada sob a perspectiva do teorema obtido na Seção 4.1.2. Neste caso, observa-se que cada interferente pode atingir, no máximo, um dos $K$ chips alocados de uma seqüência $\lambda_{1^{-}}$ OOC; isto é, para o caso de um único interferente tem-se que $p_{1}(k \cdot 1)=p$ para $k<K$, onde $p$ é a probabilidade de um chip ser ativado, já levando-se em conta a possibilidade do bit interferente ser zero ou um, expressa em (53). Logo, como decorrência de (60), obtém-se que

$$
\begin{aligned}
p_{1}(1,0) & =p_{1}(0.0)-p_{1}(0,1)=1-p \\
p_{1}(2.0) & =p_{1}(1.0)-p_{1}(1,1)=1-2 p \\
\vdots & =\vdots \\
p_{1}(k, 0) & =1-k p
\end{aligned}
$$

Portanto, na presença de $M-1$ interferentes, a probabilidade de que pelo menos $k$ chips selecionados não sofram interferência é expressa por

$$
p_{k}(M I-1)=p(k, 0)=(1-k p)^{M-1}
$$

Então, com o auxílio de (53), (61) e (71), e considerando ainda, que o evento de erro só ocorre se o bit transmitido for zero, resulta que a probabilidade de erro de bit para o código $\lambda_{1}$-OOC é dada por

$$
P_{E_{1}}=\frac{1}{2} \sum_{k=0}^{K}(-1)^{k}\left(\begin{array}{c}
K \\
k
\end{array}\right)\left(1-\frac{K}{2 F} k\right)^{M-1}
$$




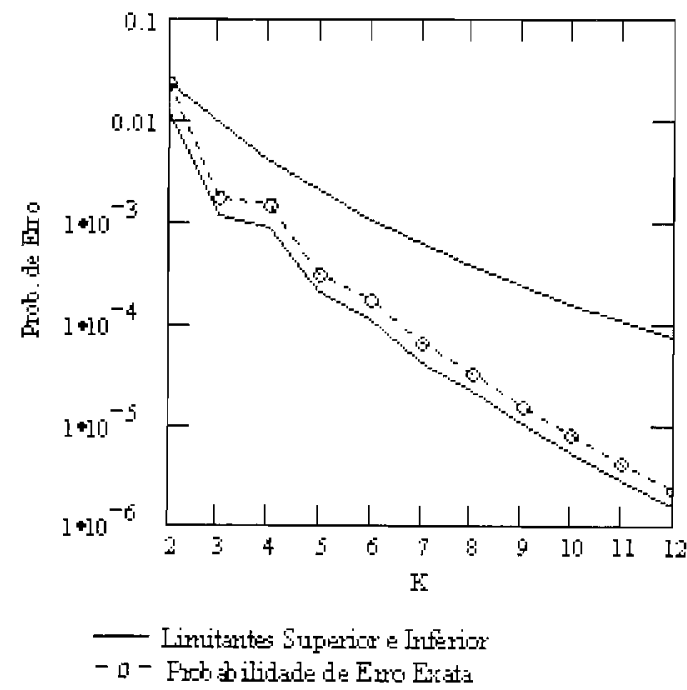

Figura 15. Comparação entre os resultados da expressão da probabilidade de erro exata para o código $\lambda_{2}$-OOC, e os seus limitantes $(F=501$ e $M=25)$.

reproduzindo a expressão obtida anteriormente em [10].

Para o código $\lambda_{2}=O O C$, até o momento, somente se dispunha de expressões para os limitantes superior e inferior da probabilidade de erro [10]. Todavia. à luz dos resultados aqui obtidos, pode-se conseguir uma expressão exata, determinando-se, inicialmente, a probabilidade de ausência de interferência em pelo menos $k$ chips escolhidos de uma seqüência $\lambda_{2}$-OOC e que, ao mesmo tempo, no mínimo um chip selecionado seja atingido, para o caso de um único interferente. Considerando-se, ainda, que todos os padrões de interferência atingem dois dentre os $K$ chips alocados, simultaneamente, obtém-se a seguinte expressão, válida para $k<K$

$$
p_{1}(k \cdot 1)=\left(1-\frac{k}{h-1}\right) p
$$

Utilizando um processo de recorrência similar àquele desenvolvido em (70), e estendendo-se o resultado para a ação de $M-1$ interferentes, pode-se concluir que, neste caso

$$
p_{k}(M-1)=\left[1-k p\left(1-\frac{k-1}{2(K-1)}\right)\right]^{M-1}
$$

Logo, a probabilidade erro de bit para o código $\lambda_{2}$-OOC pode ser obtida por intermédio de (61), conduzindo, finalmente, à seguinte expressão

$P_{e_{2}}=\frac{1}{2} \sum_{k=0}^{K}(-1)^{k}\left(\begin{array}{c}K \\ k\end{array}\right)\left[1-\frac{K}{ \pm F} k\left(2-\frac{k-1}{K-1}\right)\right]^{M-1}$

A Fig. 15 mostra o gráfico resultante da expressão obtida acima, em comparação com os limitantes disponíveis anteriormente.

A Fig. 16 mostra um conjunto de gráficos comparativos de desempenho entre os códigos OTH e OOC. Observa-se que as

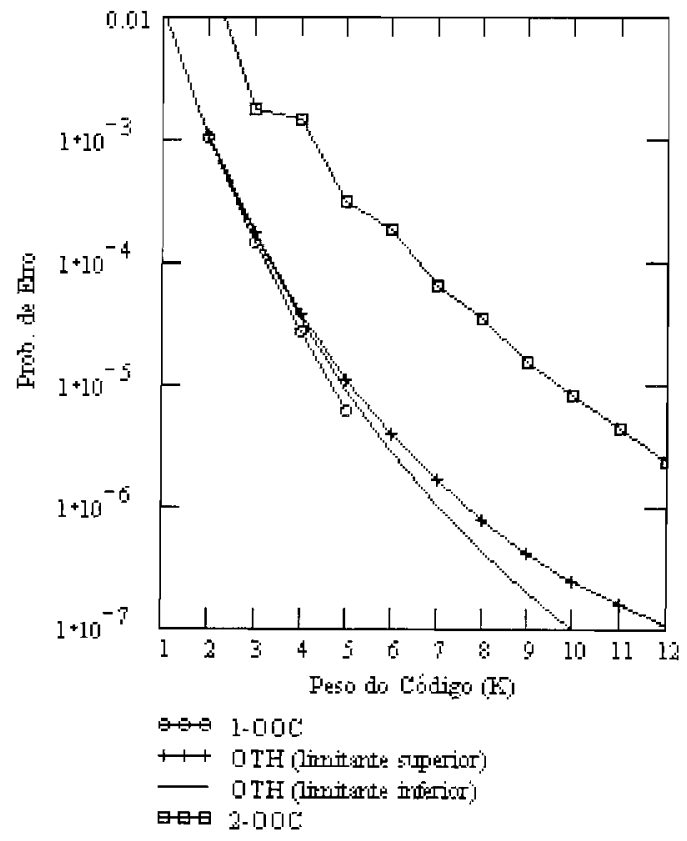

Figura 16. Desempenho dos códigos OTH e OOC para $F=$ $501 \mathrm{chips} /$ bit e $M=25$ usuários.

curvas de probabilidade de erro do código OTH são assintóticas ao $\lambda_{1}$-OOC para valores pequenos de $\mathrm{K}$, justamente onde é possível se obter sequiências $\operatorname{com} \lambda=1$. Logo, a diferença de desempenho entre esses dois códigos é, geralmente, irrelevante no domínio de existência do $\lambda_{1}$-OOC. Além disso, sem a restrição severa no número de seqüências, no caso do $\mathrm{OTH}$ é possível alocar um número de pulsos por bit maior em relação ao código $\lambda_{1}$-OOC. resultando numa probabilidade de erro bem menor para um mesmo número de usuários no sistema. Observa-se que o código $\lambda_{2}$-OOC, apesar de fornecer um desempenho inferior ao OTH, também tem o potencial de superar o $\lambda_{1}$-OOC, devido a possibilidade que se obtenham seqüências com pesos maiores, para um mesmo número de usuários e, assin, conduzindo a taxas de erro menores que a probabilidade de erro mínima do $\lambda_{1}$-OOC.

Um outro aspecto que pode ser comparado é o desempenho ótimo dos códigos para um comprimento das palavras constante, em função do número de usuários do sistema (Fig. 17). Isto implica que os sistemas sejam dimensionados adotando-se o código de maior peso possível para um dado número de usuários, no caso do $\lambda_{1}$-OOC, e utilizando-se o peso ótimo, no caso do OTH.

Observa-se que o $\lambda_{1}$-OOC somente é superior, em termos de taxa de erro, para sistemas com número de usuários muito pequeno, de fato, na região em que este código apresenta probabilidade de erro nula, isto é, quando $K_{\max }>M-1$. Os saltos bruscos observados na taxa de erro, no gráfico do OOC, são devidos ao esgotamento das seqüências para um certo valor de $K$, forçando a sua redução de uma unidade. 


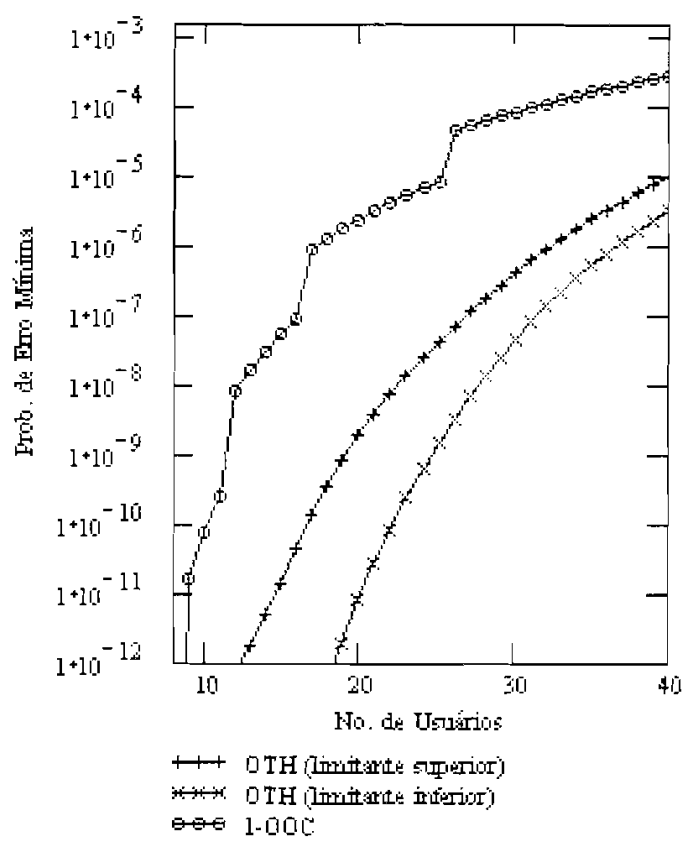

Figura 17. Probabilidade de erro mínima para os códigos $\lambda_{1}$-OOC e OTH para $F=501 \mathrm{chips} / \mathrm{bit}$.

\section{CONCLUSÕES}

A análise efetuada na Seção 3. mostra que o desempenho dos sistemas CDMA em canais unipolares varia de acordo com o tipo de sinalização adotada e a técnica de deteç̧ão escolhida. A estrutura de recepção convencional não é adequada para sistemas com sinalização podal e, por essa razão, virtualmente todos os esquemas propostos, anteriormente, para esse tipo de sinalização se baseiam nas técnicas de detecção com limitação abrupta. No entanto, ao se considerar a possibilidade de sinalização unipolar ortogonal, verifica-se que a estrutura de recepção convencional pode fornecer um desempenho similar ao dos sistemas CDMA baseados em sinalização bipolar antipodal. Além disso, a adoção de sinalização ortogonal permite, em princípio, que se compartilhe as mesmas seqüências desenvolvidas para o caso bipolar. No caso específico de CDMA óptico, a sinalização podal conduz, geralmente, a utilização de sequiências relativamente esparsas, contribuindo, assim, para a redução do ruído de batimento. Já para o caso ortogonal, a relação sinal-interferência é maximizada quando cada símbolo ocupa metade do intervalo de sinalização e, portanto, deve-se esperar um nível de ruído maior em relação ao primeiro.

Os códigos OTH constituem uma nova classe de códigos unipolares adequados para aplicações em CDMA ótico. Ao contrário dos códigos $\mathrm{OOC}$, a sua concepção não restringe, em demasia, a construção das sequiências sob o aspecto da autocorrelação e correlação cruzada. A condição necessária para viabilizar o processo de aquisição de sincronismo é a diversificação das palavras das seqüências, de modo a se obter boas propriedades globais de correlação cíclica. $\mathrm{O}$ desempenho, em termos de probabilidade de erro, dos códigos OTH aleatórios é potencialmente superior ao do OOC, especial- mente quando é necessário acomodar um número maior de usuários no sistema, devido a uma limitação inerente: o peso máximo que pode ser obtido nas sequiências OOC. Este fato sugere que a otimização das características de correlação, e a conseqüente geração de seqüências extremamente ordenadas. porém raras, impede que esses códigos liberem todo o desempenho potencial dos códigos unipolares. Por outro lado, os códigos OTH, devido a sua estrutura mais flexível, conduzem a um universo de seleção de sequiências muito maior, abrindo uma vasta gama de possibilidades a serem exploradas.

\section{REFERÊNCIAS}

[1] D. D. Sampson, G. J. Pendock and R. A. Griffin, "Photonic Code-Division Multiple Access Communications". Fiber and Integr. Optics, vol. 16, pp. 129-157, 1997.

[2] D. O. North, "An Analysis of the Factors which Determine Signal/noise Discrimination in Pulsed-Carrier Systems", Proc. IEEE, vol. 51, pp. 1016-1027, 1963.

[3] G. L. Turin, "On the Estimation in the Presence of Noise of the Impulse Response of a Random Linear Filter" IRE Trans. Inform. Theory, vol 3, pp. 5-10, 1957.

[4] P. Cielo and C. Delisle, "Multiplexage em Communicacion Optique par Interféromètrie à Grande Différence de Marche en Lùmiere Blanche." Canad. J. Phys., vol. 54 pp. 2322-2331, 1976.

[5] L. Nguyen, B. Aazhang and J. F. Young, "All-Optical CDMA with Bipolar Codes." Electr. Letters, vol. 31 , pp. 469-470, 1995.

[6] R. L. Pickholtz, D. L. Schilling and L. B. Milstein, "Theory of Spread-Spectrum Communications - A Tutorial" IEEE Trans. on Comm., pp. 855-884, May 1982.

[7] J. A. Salehi and C. A. Brackett, "Code Division Multiple-Access Techniques in Optical Fiber Networks - Part II: Systems Performance Analysis." IEEE Trans. Comm., pp. 834-842, 1989.

[8] F. R. K. Chung, J. A. Salehi and V. K. Wei, "Optical Orthogonal Codes: Design, Analysis, and Applications", IEEE Trans. Inform. Theory, vol. IT-35, pp. 595-604, May 1989

[9] J. A. Salehi "Code Division Multiple Access Techniques in Optical Fiber Networks - Part I: Fundamental Principles", IEEE Trans. Commun., vol. 37, pp. 824833, Aug. 1989.

[10] M. Azizoglu, J. A. Salehi, and Y. Li, "Optical CDMA via Temporal Codes", IEEE Trans. Commun., vol. 40, pp. 1162-1170, Jul. 1992.

[11] P. A. Davies and A. A. Shaar, "Asynchronous Multiplexing for an Optical Fibre Local Area Network", Electron. Lett., vol. 19, no. 10, pp. 390-392, May 1983.

[12] A. A. Shaar and P. A. Davies, "Prime Sequences: QuasiOptimal Sequences for OR Channel Code Division Multiplexing", Electron. Lett., vol. 19, no. 21, pp. 888889, Oct. 1983. 
José Santo Guiscafré Panaro formou-se em Engenharia Eletrônica pela Universidade Federal do Rio de Janeiro (UFRJ) em 1980 e cursou a pós-graduação em Engenharia de Comunicações de Dados no Instituto Nacional de Telecomunicações (INATEL) em 1995. Atualmente participa do programa de doutorado no Departamento de Comunicações da Faculdade de Engenharia Elétrica e de Computação da UNICAMP. Atuou como engenheiro de desenvolvimento na indústria de informática entre 1981 e 1994, especialmente na área de armazenamento de dados. Atualmente é professor adjunto do INATEL. Seus interesses de pesquisa incluem a teoria de comunicação, sistemas de múltiplo acesso, processamento de sinais, gravação magnética e criptografia.

Celso de Almeida nasceu em Jundiaí, S.P., em 1957. Recebeu o diploma de Engenharia Elétrica, modalidade Eletrônica. pela UNICAMP em 1980. Recebeu os títulos de Mestre e Doutor em Engenharia Elétrica, modalidade Telecomunicações, também pela UNICAMP em 1983 e 1990, respectivamente. Trabalhou de 1983 a 1990 na Elebra Telecom no desenvolvimento de Sistemas de Comunicações Ópticos. É professor concursado da Faculdade de Engenharia Elétrica e de Computação da UNICAMP desde 1990. Recebeu o título de Professor Livre Docente pela UNICAMP em 1998. Seus principais interesses em pesquisa são em CDMA, Comunicações Ópticas, Transmissão Digital, Códigos Controladores de Erros e Criptografia. 